\title{
JOKE-WORK: THE CONSTRUCTION OF JEWISH POSTMODERN IDENTITY IN CONTEMPORARY THEORY AND AMERICAN FILM
}

\author{
Ruth D. Johnston \\ Pace University

\section{Introduction}

This paper argues that contemporary European postmodern theory and Jews' self-representations in recent American films both construct Jewish postmodern identity in terms of Freud's definition of the self-critical tendentious joke in Jokes and Their Relation to the Unconscious. At the same time, the paper demonstrates how each deployment of the joke-work emphasizes a different aspect of its narrative process and accordingly articulates a different definition of communal affiliation.

\section{Part I: The Construction of the Jew in Postmodern Theory}

The terms "Jew" and "postmodern" are very closely linked. For the Jew has become a trope of otherness in contemporary European postmodern theory, which is preoccupied with undoing all forms of "essentialism" insofar as it is energized by the trauma of the historical experience of Nazism and the effort to re-think modern antiSemitism. Thus in “The Jewish People Don't Dream” Philippe Lacoue-Labarthe and Jean-Luc Nancy "attempt, after Auschwitz, to imagine what would constitute a distinctly Jewish process of identification" and to offer "an alternative to the 'identificatory mechanisms"” that, according to their earlier essay "The Nazi Myth," "are inevitably complicitous with fascism." For such mechanisms privilege the concept of "type" or "singular identity" and thus necessarily exclude the Jew (defined as the "antitype") from German national identity. Lacoue-Labarthe and Nancy locate in Freud's Der Witz (Jokes and Their Relation to the Unconscious) a distinctly Jewish identificatory process: "The mocker participate[s] in the defect being mocked. In other words . . . the Witz is best realized by means of an identification stretching across a doubled, or collective identity." ${ }^{2}$ At the same time, the authors recognize that the doubling of identity in the joke structure might problematize the notion of identity per se: "Perhaps one must discern here . . . a path . . . which above all would draw analysis beyond or outside itself, and . . . beyond any identifiable 'Jewishness.' One way or another, this path would lead beyond the identity principle." ${ }^{3}$

According to a number of critics of postmodern theory, despite its philo-Semitic ambitions, the participation in a "discourse of the Jew" has little to do with actual Jews. For it merely reverses and idealizes the qualities that were previously stigmatized in the discourse of modern anti-Semitism. So for these critics the "Jewish question" remains alive and unresolved in postmodern theory.

At this juncture we may ask, is "the Jewish question" of postmodern theory also as central a preoccupation in the United States, where the situation of Jews may perhaps be described more accurately as "post-assimilationist" rather than postHolocaust? Here Jews are not merely tropes circulated by others. Nevertheless, their participation in the multiculture also entails producing Jewish difference via doubling and performance. ${ }^{4}$ In a recent essay, Homi Bhabha in fact analyzes the tendentious, self-critical joke as "a mode of [Jewish] minority utterance" ${ }^{5}$ precisely because of the 
doubling or ambivalence that Lacoue-Labarthe and Nancy find problematic. And he adds that this focus on the joke-work shifts the definition of difference from visible or visual marks to "verbal or rhetorical locutions."

Bhaba isolates four aspects of the tendentious self-critical joke that I will mobilize in my analysis: narrative structure, iterative process, performance, and ethical dimension. His analysis focuses first on the narrative structure of the Jewish joke, which produces a double subject-the "subject of the jest (sujet d'énonce)" or object of fun viewed extrinsically and "the subject of the joke-work (sujet d'énonciation)," which is not so much a specific person as a process of narration. ${ }^{7}$

This doubling of subjects produces a self-critical posture, which Freud describes as "criticism directed against the subject himself, or to put it more cautiously, against someone in whom the subject has a share-a collective person, that is (the subject's own nation for instance)." 8 Bhabha explains that it thereby avoids essentialism because it offers a mode of cultural affiliation that results from ambivalence rather than from a confrontation between insiders and outsiders.

Secondly, Bhabha remarks that communal identification involves an iterative process, which "has initially to turn upon a destabilizing encounter with alterity prior to the affiliative bond." 9 Moreover, this iterative process does not accommodate a transcendent perspective existing apart or prior to the cultural performance.

If the representation of the joke-work as an iterative process suggests its performativity, Bhabha ends his discussion by focusing on two aspects that work in tandem: the performance of the joke, specifically, the importance of timing, and the joke's ethical dimension, which involves taking into account the hearer. ${ }^{10}$ This ethical dimension involves the uncertainty of truth, or as Freud puts it, the question of "what determines the truth .... Is it the truth if we describe things as they are without troubling to consider how our hearer will understand what we say? . . . does not genuine truth consist in taking the hearer into account .... What [such jokes attack] is not a person or an institution but the certainty of our knowledge itself . . .." As Bhabha explains, the success of the joke depends on the third person, neither the joker nor the object of the joke: "To take the hearer into account is to share in the making of a 'collective person'-nation, community, group-from the ambivalent movement that circulates in between first and third persons." ${ }^{12}$ In short, what Bhabha adds to Lacoue-Labarthe and Nancy's analysis of the joke-work's identificatory mechanism is the third person's function in the constitution of community-the translation/transformation of the identificatory process by the ethical dimension.

\section{Part II: Joke-work in Woody Allen's Cinema}

Woody Allen's humor is most frequently characterized as drawing on the tradition of the schlemiel, defined by Jon Stratton as "a character in a joke" who "provides the community with an opportunity to laugh at its own circumstance and at the dominant society that has placed it in this circumstance."13 However, this definition assumes an already consolidated communal identity. In this connection David Biale argues, "In some of Allen's movies the Jew's sexual ambivalence infects the gentile women and turns them into mirror images of himself: even gentile Americans become 'Jewish.' The hidden agenda is to identify American with Jewish culture by 
generalizing Jewish sexuality and creating a safe, unthreatening space for the schlemiel as American anti-hero." ${ }^{14}$ But this explanation addresses the extension of Jewish qualities to gentile characters within the diegesis, not how Allen manages to implicate the spectator.

From this perspective, the joke structure provides a better mode of analysis. For the focus on characters omits the crucial role of the subject of the joke-work, defined by Bhabha as a process of narration rather than as a person. An example of the complexity of this process in Annie Hall (1977) is the split screen sequence that foregrounds the behavioral differences between the Halls and the Singers and pokes fun at both. After a stand-up performance in Wisconsin, Alvy Singer (Allen's character) visits the Halls with Annie (Diane Keaton). The Halls sit quietly around the Easter dinner table, complimenting the ham and talking about boating. A scene at the Singer dinner table is inserted for high contrast. Mother Singer stands, and everyone speaks loudly and at once about failure and disease. Yet if this juxtaposition exposes the Singers' lack of civility, it does not idealize the Halls. Grammy Hall's anti-Semitism is represented via Alvy's sudden transformation into a Hasidic Jew wearing traditional garb, a full beard, and side locks. Also, later scenes at the Halls expose the father's alcoholism and brother Duane's suicidal tendencies, which belie the surface calm and politeness of the dinner scene. In short, the narrative process places the spectator in a critical position (which does not rule out sympathy) in relation to all the characters.

However, another aspect of the representation of the Jew needs further elaboration at this point: the issue of gender. The traditional schlemiel was always male. And Biale focuses on the Jew as male sexual schlemiel. Many critics have demonstrated the intersection of racial and sexual categories in European constructions of the Jew. For instance, Sander Gilman argues that Jewish males were seen as feminized women largely because of the ritual practice of circumcision. ${ }^{16}$ As a result, comments Ann Pellegrini, "the Jewishness of male Jews became as much a category of gender as of race." This leads her to observe that "in the homology Jewas-woman, the Jewish female body goes missing." 17

In the American context, the representation of the feminized Jewish male is transformed into material for humor, but the question remains: where does the representation of the Jewish male as sexual neurotic leave Jewish women, especially since the Jewish male so often longs for a gentile woman, who, as Biale observes, becomes the schlemiel's mirror or double. The Jewish female thus seems to be doubly displaced.

Here we might invoke the structure of another tendentious joke analyzed by Freud: the "dirty joke" or smut, in which the woman functions as the butt of the joke and is structurally excluded. As Mary Ann Doane comments, "In order for the dirty joke to emerge in its specificity . . . the object of desire-the woman-must be absent and a third person (another man) must be present as witness to the joke-'so that gradually, in place of the woman, the onlooker, now the listener, becomes the person to whom the smut is addressed . . .."'18 Here the doubled subject of the self-critical joke is displaced by a gendered subject/object binary, and the exclusion of the woman as object facilitates the forging of a homosocial relation between the teller and the listener, both constructed as masculine. 
The structure of the "dirty joke" is certainly operative in the representation of the Jewish woman as a "Jewish American Princess," or JAP. In contrast to the "comic and perhaps loveable" male sexual schlemiel, the JAP stereotype is characterized as "obsessively materialistic . . . and utterly uninterested in sex." ${ }^{19}$ Moreover, in terms of the joke structure, whereas the male's "inner conflicts and neuroses are revealed and thus [made] sympathetic, .... [the JAP's] sexual pathology remains purely objectified and superficial. Jewish women become the site for projections of all that seems most hateful about Jewish sexuality." 20

Woody Allen's film career coincides with the emergence of the JAP stereotype in the post-assimilationist $1970 \mathrm{~s},{ }^{21}$ and not surprisingly, his humor includes jokes that target the Jewish woman. In Annie Hall, the Jewish woman as JAP makes a cameo appearance as an ex-wife who is characterized by her social ambition and lack of interest in sex.

\section{Part III: Joke-work in Kissing Jessica Stein}

The representational challenge for contemporary feminist films is to resist the Jewish woman's systematic exclusion from representation by reclaiming Woody Allen territory and swapping the roles of male schlemiel and JAP, which are distinguished primarily by the different perspectives from which they are viewed. Thus Kissing Jessica Stein [directed by Charles Herman-Wurmfeld, 2001; written by Jennifer Westfeldt and Heather Juergensen] transforms the JAP into the female schlemiel whose sexual neuroses and inner conflicts move to center stage and are explored sympathetically, while the Jewish male is either objectified or excluded altogether as object of desire.

Accordingly, Kissing Jessica Stein has been described as a lesbian Annie Hall by a number of reviewers. ${ }^{22}$ Others dismiss the film as "just two straight women's [inaccurate] interpretation of a lesbian relationship." ${ }^{3}$ To a certain extent, the plot conforms to Terry Castle's description of "the underlying principle of lesbian narrative itself," which depends on the suppression of "male erotic triangulation," i.e., the triangular desire defined by René Girard as being generated by the rivalry of two men over a woman, ${ }^{24}$ which coincidentally also describes the structure of the "dirty joke." Thus Jessica, after a series of disastrous first dates with men decides to answer a personals ad which contains a quotation from her favorite writer, Rilke. The quotation is about overcoming the shyness that prevents one from opening oneself to the experience of an other. Helen Cooper, an assistant art gallery director who is simultaneously juggling three shallow relationships with men, has placed the woman seeking woman ad after receiving a long, considering look from a woman attending an opening at the gallery, who is shown earlier kissing another woman. Thus male erotic triangulation is suppressed for different reasons for the two characters, which in turn may account on the one hand for the "'dysphoric' lesbian counterplotting" of Jessica's story (i.e., "female homosexual desire is a finite phenomenon-a temporary phase in a larger pattern of heterosexual Bildung") and on the other hand for the "'euphoric' lesbian counterplotting" that describes Helen's story (i.e., the failure of heterosexual love "functions as a pretext for the conversion to homosexual desire" and offers an alterative to the marriage plot). ${ }^{25}$ For the film ends with the suggestion that Jessica will again become involved with ex-lover/boss Josh while Helen has moved on to another woman. 
Yet however nuanced, Castle's description of lesbian narrative does not quite fit Kissing Jessica Stein, which is neither a lesbian nor a straight film, for it escapes such definitive categorization and rather explores the characters' sexual fluidity. If Jessica is "straight," she is queerly so, for she falls in love with another woman and is happiest when she is with Helen. In a scene near the end of the film she explains to Josh that Helen "dumped" her because she "wanted someone a little more gay." The wording is interesting in that Jessica, who is fussy about language, does not describe herself as straight. Through Jessica's character the film explores the possibility of romantic love that does not depend on physical expression as well as the eroticism of female friendship (as when Jessica caresses Helen's pants in a taxi and says, "What are these? I'm so borrowing"). Her choice of words also calls into question the assumptionmentioned in a number of reviews - that she and Josh will start dating again.

As for Helen, is she lesbian or bisexual? Though at the end of the film she is sexually involved with another woman, it is premature to conclude that this is the end of her trajectory, for her bisexuality has not been presented as a denial either of lesbianism or of heterosexuality. As she tells Jessica, she "find[s] lots of things sexy." So for both characters, the ending avoids the definitive closure upon which Castle's categories depend. And in any case, the film emphasizes the cadence, not the resolution, of Helen and Jessica's romance.

Resisting all rigid definitions of sexuality, Kissing Jessica Stein instead investigates the multiple aspects of sexual attraction. For instance, when Jessica comes out to her friend Joan about her relationship with Helen, Joan asks, "What's she like?" Jessica's reply reveals that Helen has all the qualities she has been seeking: she's "kind and witty, quirky, nurturing"; "the sex is good"; Helen "makes [her] laugh," and she's "as smart as" Jessica. Finally, Joan asks, "and she gets you?" to which Jessica responds, "Yeah, she does; she really does." "Gets you" is noteworthy because "getting" is a term associated with the reception of a joke and suggests an instantaneous effect: the coincidence of understanding and induced laughter. As Doane explains, the timing is all important because if one does not "get" the joke at the moment of transmission, one will never "get" it, even if one belatedly comprehends it. For in "getting" the joke, one "finds oneself" laughing; "finds oneself" suggests that one is "beside oneself," other than oneself. ${ }^{26}$ In short, "getting" involves a split or doubled subject. So the doubling of the listener mirrors the doubling of the subject of the joke-work, which in turn enables the construction of a non-essentialized community.

The spectator too is invited to "get" Kissing Jessica Stein precisely insofar as Helen and Jessica's multi-faceted mutual attraction is presented largely through their language rather than explicit acts, which would appeal to the spectator's voyeurism-a structure which depends on the spectator's separation from, rather than implication in, the iterative narrative process. Their first date almost doesn't happen because Jessica panics and wants to leave immediately. Upon hearing Helen say, "You don't have to make up your mind right away; let it marinate," Jessica is struck by this use of "marinate" and agrees to stay for a drink. Next she is fascinated by Helen's term "sexy/ugly." For it not only introduces Jessica to a new way of conceiving of sex appeal, but it also picks up on and formally mimics Jessica's descriptions of men she's been dating as not the right kind of smart and not the right kind of funny (funny/stupid or funny/tragic). Of particular interest are those occasions when the 
women reveal their sexuality even though they seem not to be discussing sex at all. For instance, during their taxi ride to a restaurant (after they've clearly clicked over drinks) Jessica admires the color of Helen's lipstick. Helen explains that she uses three different shades to achieve it and she gives Jessica the recipe, observing that it would look equally good on her. Jessica replies that using multiple shades is "too labor intensive" and that she's "looking for that one," to which Helen counters, "You'll never find it. You have to blend." In this dialogue sexuality exists as an in-between state located in the "play" between an "innocent" and a "loaded" meaning.

Of course, as a film, Kissing Jessica Stein does not depend on dialogue alone but translates double entendre into visual terms as a dialectic of revealing and concealing or a play between the visible and the verbal. (The verbal thereby retains its importance in defining difference in this film, as in Bhabha's analysis of the joke-work.) Of particular interest to my argument is the function of visual double entendre as a mechanism of identification, which engages the spectator on the basis of such doubling. A good example is the scene in a bar in which two men join Jessica and Helen's table, and the topic of male obsession with lesbian sex comes up. Helen and Jessica are seated side by side on one end of the table, each with her chin resting on her right hand, a pose that emphasizes their doubling. Then, as the men try to explain what turns them on about seeing two women together, Helen enacts under the table what they describe in their conversation. In effect, the table splits the screen horizontally. When one man mentions the excitement of seeing two women touching, we see Helen caress Jessica's thigh, her hand concealed from the men's view. The scene pokes fun at-without cruelly mocking - the men's voyeuristic desires even as it withholds their satisfaction. At the same time, it offers the spectator visual access to Helen's seduction of Jessica yet transforms that voyeuristic pleasure into an occasion for laughter. The hidden touching turns the women on too, for shortly thereafter they head for home, using as an excuse their concern about Jessica's having suddenly developed "a slight leg cramp." When they leave, one of the men comments with genuine appreciation, "Women really know how to take care of one another." And of course, he speaks more truly than he knows.

\section{Conclusion}

Like many Woody Allen films, Kissing Jessica Stein uses the "opposites attract" premise yet escapes the binary logic of the premise by resisting containment by the stereotype; for the relation between Jessica and Helen queers the straight/lesbian binary and in general resists rigid identity categories. It thus undoes the exclusion of the Jewish woman from the diegesis as it makes a space for the female sexual schlemiel.

But even more important is Kissing Jessica Stein's deployment of joke-work on the level of enunciation and its intervention in the construction of Jewish/postmodern communal identity as joke-work. First of all, Kissing Jessica Stein corrects the gender imbalance of Allen's cinema on the level of enunciation by making room for the female spectator. Furthermore, by foregrounding the process of "getting" a joke, it also enriches Bhabha's analysis of this "mode of minority discourse" (which insists upon the importance of the third person) by demonstrating that the hearer/spectator participates in the construction of a non-essentialized collective identity only insofar as $\mathrm{s} /$ he mimics the doubling of the subject of the joke-work. For in "getting" a joke, 
one "finds oneself" laughing. This finding of oneself assumes that one is other. In short, the psychic force of the affect (the laughter as unconscious excess) provides a limit that prevents one from coinciding with oneself as it displaces any conception of social enunciation as a direct expression of one's cultural self-presence.

\section{NOTES}

1. Elizabeth Jane Bellamy, Affective Genealogies: Psychoanalysis, Postmodernism, and "The Jewish Question" After Auschwitz (Lincoln: University of Nebraska Press, 1997), 146.

2. Qtd. in Bellamy, Affective Genealogies, 96.

3. Qtd. in Bellamy, Affective Genealogies, 98; emphasis in original.

4. Jon Stratton, "Not really white-again: performing Jewish difference in Hollywood films since the 1980s," Screen 42.2 (Summer 2001), 156.

5. Homi K. Bhabha, "Foreword: Joking Aside: the Idea of a Self-Critical Community" in Modernity, Culture and "The Jew", ed. Bryan Cheyette and Laura Marcus (Stanford: Stanford University Press, 1998), xx.

6. Bhabha, "Foreword," xvi.

7. Bhabha, "Foreword," xvii.

8. Sigmund Freud, Jokes and Their Relation to the Unconscious, trans. James Strachey (New York: Norton, 1960), 111.

9. Bhabha, "Foreword," xviii, xix.

10. Bhabha, "Foreword," xix.

11. Freud, Jokes, 115.

12. Bhabha, "Foreword," $x x$; emphasis in original.

13. Jon Stratton, Coming Out Jewish: Constructing Ambivalent Identities (New York: Routledge, 2000), 301.

14. David Biale, Eros and the Jews: From Biblical Israel to Contemporary America (Berkeley: University of California Press, 1997), 207.

15. Biale, Eros, 205.

16. The circumcised penis and the clitoris are both regarded as truncated penises. Sander L. Gilman, Freud, Race, and Gender (New York: Routledge, 1993), 38-39.

17. Ann Pellegrini, Performance Anxieties: Staging Psychoanalysis, Staging Race (New York: Routledge), 17, 18.

18. Mary Ann Doane, Femmes Fatales: Feminism, Film Theory, Psychoanalysis (New York: Routledge, 1991), 30.

19. Biale, Eros, 207.

20. Biale, Eros, 207.

21. Riv-Ellen Prell, “Why Jewish Princesses Don't Sweat: Desire and Consumption in Postwar American Jewish Culture" in Too Jewish? Challenging Traditional Identities, ed. Norman Kleeblatt (New Brunswick, N. J.: Rutgers University Press, 1996), 84.

22. Elvis Mitchell, Rev. Kissing Jessica Stein, New York Times (March 13, 2002), sect. E, 5.

23. Sherri Whatley, Rev. Kissing Jessica Stein, Off Our Backs (July-August 2002), 66.

24. Marjorie Garber, Vice Versa: Bisexuality and the Eroticism of Everyday

Life (New York: Simon and Schuster, 1995), 427.

25. Garber, Vice Versa, 428.

26. Doane, Femmes Fatales, 40-41. 